\title{
Separation, Quantification and Control of Enatiomers of the Key Starting Material of Dextromethorphan Hydrobromide
}

\author{
Ajit Anerao*, Vishal Solase, Amol More, Nitin Pradhan \\ R\&D Centre (API), Wanbury Ltd., EL-16, TTC Industrial Estate, Mahape, Navi Mumbai 400710, India.
}

\section{ARTICLE INFO \\ Article history: \\ Received on: 16/05/2018 \\ Accepted on: 11/07/2018 \\ Available online: 31/08/2018}

\section{Key words:}

HPLC; chiral purity;

dextromethorphan;

development; validation.

\begin{abstract}
Objective: Enantiomeric resolution of racemic 1-(4-Methoxybenzyl)-1,2,3,4,5,6,7,8-octahydroisoquinoline, a key starting material in the synthesis of the antitussive agent dextromethorphan hydrobromide. Material and method: Chiral liquid chromatographic method is developed and enantiomers are resolved on a Chiralpak ID-3 column using gradient mode of elution. Mobile phase A and B containing a mixture of $0.1 \%$ diethylamine in acetonitrile and $0.1 \%$ diethylamine in methanol respectively are optimized with the timed programme. The flow rate is $1.0 \mathrm{~mL} / \mathrm{minute}$ and the column temperature was maintained at $40^{\circ} \mathrm{C}$. Ultraviolet detection was performed at $280 \mathrm{~nm}$ wavelength and the injection volume was $20 \mu \mathrm{L}$. Results: The resolution between the enantiomers is found to be more than 2.5. The developed method is extensively validated and proved to be robust. The limit of detection and limit of quantification of unwanted (R)-enantiomer is found to be $0.0075 \%$ and $0.025 \%$ with respect to test concentration, respectively. The percentage recovery of (R)-enantiomer is ranged from 88.6 to 106.6 in (S)-(-)-1-(4-Methoxybenzyl)-1,2,3,4,5,6,7,8octahydroisoquinoline sample solution. Conclusion: The proposed method is found to be suitable and accurate for the quantitative determination of (R)-enantiomer in the key starting material of the dextromethorphan hydrobromide bulk drugs.
\end{abstract}

\section{INTRODUCTION}

Dextromethorphan hydrobromide is the pharmacologically active ingredient of NUEDEXTA that acts on the central nervous system (CNS). The chemical name is Morphinan, 3-methoxy-17-methyl-, $(9 \alpha, 13 \alpha, 14 \alpha)$, hydrobromide monohydrate (Rxlist, 2017). Dextromethorphan is the d-isomer of 3-methoxy-N-methyl-morphinan, a synthetic analog of codeine. D-Methorphan is widely used all over the world as an overthe-counter (OTC) medication to treat a cough (PDR, 2018; Magellan Rx Management, 2016; Cersósimo and Micheli, 2007; EMA, 2013). Levomethorphan is the 1-isomer of 3-methoxy-Nmethyl-morphinan and, unlike d-methorphan, is a potent narcotic analgesic. For this reason, levomethorphan is not commercially available and in some countries, it is listed as a controlled substance (Bortolotti et al., 2013). Dextromethorphan is an official

${ }^{*}$ Corresponding Author

Ajit Anerao, R\&D Centre (API), Wanbury Ltd., EL-16, TTC Industrial

Estate, Mahape, Navi Mumbai 400710, India.

E-mail:ajit.anerao@wanbury.com drug listed in the United State Pharmacopeia (USP) (USP, 2017) as well as European Pharmacopeia (EP) (EDQM, 2017). In USP 40 , the unwanted levomethorphan is tested by high-performance liquid chromatography (HPLC) method and controlled with the limit $0.10 \%$ while in EP 9.0 it is controlled with an optical rotation method. Recently in the month of March 2018, EP has published a draft monograph by including enantiomeric selective HPLC method in Pharmeuropa (Pharmeuropa, 2017). Owing to serious incidents due to the abnormally high concentration of levomethorphan in dextromethorphan, it is proposed by Pharmeuropa to add a test for enantiomeric purity by LC, which is more specific than the current test of optical rotation. The chiral center responsible for the formation of levomethorphan is generated in the synthetic process while cyclization and formation of the key starting material, 1-(4-Methoxybenzyl)-1,2,3,4,5,6,7,8octahydroisoquinoline. Racemic 1-(4-Methoxybenzyl)-1,2,3,4,5, $6,7,8$-octahydroisoquinoline is further resolved in the synthetic process using resolution agents like tartaric acid, mandelic acid or (R)-2-(6-methoxy-2-naphthyl) propionic acid (Divi et al. 2012; Demian et al., 2000). As per International Council of Harmonization 
(ICH) guideline Q3A R2, during drug development, it is necessary to list out and discuss all possible process impurities, degradants, raw materials, intermediates, reagents and catalysts used in the manufacturing drug substance. Impurity formation, their source of origin, control, fate and purge to be studied in order to establish safety, efficacy, and quality of drug substance (ICH, 2006). On basis of the synthetic chemistry of manufacturing dextromethorphan, it is required to control the unwanted enantiomer i.e. (R)-(+)1-(4-Methoxybenzyl)-1,2,3,4,5,6,7,8-octahydroisoquinoline, immediately after resolution to avoid further carry over to the final product.

In the literature number of methods have been described for the determination of levomethorphan in dextromethorphan employing various techniques such as chiral HPLC (USP, 2017; Pharmeuropa, 2017; Kikura et al. 2011) and capillary electrophoresis (Krait et al. 2018; Lurie and Kimberly, 2005) but only one method is found to control the unwanted enantiomer in key starting material (Guangyue et al. 2016). In that reported method, both enantiomers were separated on chiralcel OJ-H column with mobile phase a mixture of hexane, isopropyl alcohol, and ethanolamine but this method is not selective. The d-mandelic acid used for the resolution of the racemic 1-(4-Methoxybenzyl)$1,2,3,4,5,6,7,8$-octahydroisoquinoline is not eluting in this method. Hence the method is not suitable for the intended purpose. The major objective of the present work is to develop a method for the separation of R-isomer and S-isomer of 1-(4-Methoxybenzyl)$1,2,3,4,5,6,7,8$-octahydroisoquinoline and the method should be selective and have a low limit of detection and quantification (LOD and LOQ) values. Further, the use of immobilized chiral HPLC column ensures the column life, unlike glycoprotein-based columns. This method was successfully validated according to the ICH guidelines of method validation (ICH, 2005).

\section{MATERIALS AND METHODS}

\section{Method of analysis}

\section{Instrumentation}

Shimadzu high-performance liquid chromatography (HPLC) system LC-2010 CHT with UV detector with LC solutions software or its equivalent.

\section{Chemicals and reagents}

HPLC column used by Daicel Corporation, Chiralpak ID-3, length $250 \mathrm{~mm}$, internal diameter $4.6 \mathrm{~mm}$, particle size $3 \mu \mathrm{m}$. (S)-1-(4-Methoxybenzyl)-1,2,3,4,5,6,7,8-octahydroisoquinoline standard was procured from Roopa Industries Ltd, Hyderabad, India of potency $92.6 \%$ and (R)-1-(4-Methoxybenzyl)$1,2,3,4,5,6,7,8$-octahydroisoquinoline standard was synthesized at Wanbury R\&D Center of potency $90.6 \%$. Both standards were characterized by NMR, mass, IR and SOR and structures were confirmed. Acetonitrile, methanol and diethylamine HPLC grade from Merck was used in the experimentation. During method development, Daicel chiral stationary phases Chiralpak IG, Chiralpak AD-H, Chiralpak OJ-H and Phenomenex Lux amylose-2 were used for the trial purpose.

\section{Chromatographic parameters}

HPLC method was performed using a Chiralpak ID-3 HPLC column. Separation and peak symmetry were achieved with gradient elution of mobile phase A and B. Mobile phase A was $0.1 \%$ diethylamine in acetonitrile and mobile phase $\mathrm{B}$ was $0.1 \%$ diethylamine in methanol. The gradient elution with timed programme $\mathrm{T}_{\min } / \mathrm{A}: \mathrm{B}: \mathrm{T}_{0} / 100: 00 ; \mathrm{T}_{10} / 100: 00 ; \mathrm{T}_{15} / 00: 100$; $\mathrm{T}_{25} / 00: 100 ; \mathrm{T}_{27} / 100: 00$ and $\mathrm{T}_{40} / 100: 00$ with flow rate $1.0 \mathrm{~mL} / \mathrm{min}$ was applied. The column temperature was maintained at $40^{\circ} \mathrm{C}$. Ultraviolet detection was performed at $280 \mathrm{~nm}$ wavelength and the injection volume was $20 \mu \mathrm{L}$. Run time for blank, system suitability solution and test solution is 40.0 minutes and for a standard solution, it is 10.0 minutes.

\section{Solution preparation}

\section{Diluent preparation}

A mixture of an equal volume of methanol and acetonitrile was prepared.

\section{Standard stock solution- $A$}

Accurately weighed and transferred $30.0 \mathrm{mg}$ of (R)-1-(4Methoxybenzyl)-1,2,3,4,5,6,7,8-octahydroisoquinoline standard into $50 \mathrm{~mL}$ volumetric Flask. Dissolved and diluted up to the mark with diluent.

\section{Standard stock solution-B}

Transferred the standard stock solution-A $5.0 \mathrm{~mL}$ into 50 $\mathrm{mL}$ volumetric Flask. Dissolved and diluted up to the mark with diluent.

\section{Standard solution}

Further transferred $10.0 \mathrm{~mL}$ of standard stock solution-B into $20 \mathrm{~mL}$ volumetric flask and dilute up to mark with diluent.

\section{System suitability solution}

Accurately weighed and transferred $60.0 \mathrm{mg}$ of (S)-1-(4Methoxybenzyl)-1,2,3,4,5,6,7,8-octahydroisoquinoline standard into $20 \mathrm{~mL}$ volumetric flask. Transferred $10.0 \mathrm{~mL}$ of standard stock solution-B, dissolved and diluted up to the mark with diluent.

\section{Test solution}

Accurately weighed and transferred $60.0 \mathrm{mg}$ of the test sample into $20 \mathrm{~mL}$ volumetric flask. Dissolved and diluted up to the mark with diluent.

\section{Procedure}

Injected blank followed by system suitability solution, standard solution six times and test preparation in duplicate. The chromatograph was run for 40.0 minutes and the chromatogram recorded. The retention time of (S)-1-(4-Methoxybenzyl)-1,2,3, $4,5,6,7,8$-octahydroisoquinoline is 6.1 minutes and (R)-1-(4Methoxybenzyl)-1,2,3,4,5,6,7,8-octahydroisoquinoline is 8.0 minutes. Both isomer peaks were integrated into system suitability and test solution and unwanted $\mathrm{R}$ enantiomer were calculated by external standard addition method. 


\section{Acceptance criteria for system suitability}

The peaks of (S)-1-(4-Methoxybenzyl)-1,2,3,4,5,6,7,8octahydroisoquinoline and $\mathrm{R}$ enantiomer in system suitability solution was found a base to base separated and the resolution between both isomers was more than 2.5 .

\section{RESULTS \& DISCUSSION}

\section{Analytical method development}

1-(4-Methoxybenzyl)-1,2,3,4,5,6,7,8-octahydroisoquinoline is an optically active compound with the single chiral center. The molecular formula is $\mathrm{C}_{17} \mathrm{H}_{23} \mathrm{NO}$ and molecular weight 257.37 (CAS, 2018). Optical rotation of $\mathrm{S}$ enantiomer is $[\alpha] 20 / \mathrm{D}-152^{\circ}$, c $=1$ in chloroform with CAS No. 30356-07-1 (CAS, 2018). Optical rotation of $\mathrm{R}$ enantiomer is $[\alpha] 20 / \mathrm{D}+152^{\circ}, \mathrm{c}=1$ in chloroform with CAS No. 30356-08-2 (Sigma-Aldrich, 2018; CAS, 2018). Refer structure of both isomers in Figures. 1 and 2. It is UV active compound with strong chromophores of phenyl and quinoline aromatic rings. The solubility of both isomers was checked in various polar to non-polar organic solvents and found that those are soluble in methanol, acetonitrile, isopropyl alcohol, methylene chloride and chloroform. It is very slightly soluble in n-hexane but found practically insoluble in water. On basis of chemical properties and literature survey, it was decided to start method development using normal phase chiral HPLC technique with ultra-violet (UV) detector.

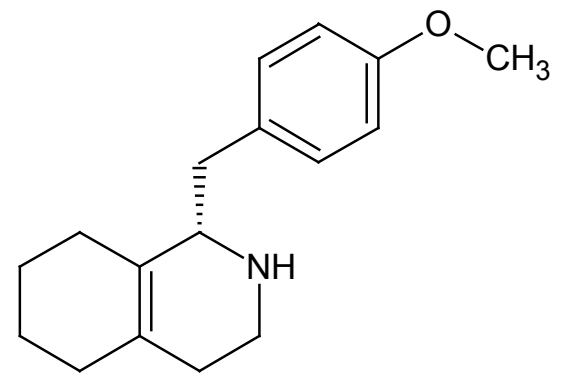

Fig. 1: Structure of the key starting material (S)-1-(4-Methoxybenzyl)-1,2,3,4, $5,6,7,8$-octahydroisoquinoline.

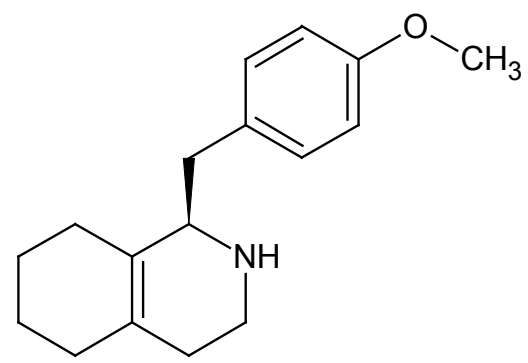

Fig. 2: Structure of unwanted isomer (R)-1-(4-Methoxybenzyl)-1,2,3,4,5,6,7,8octahydroisoquinoline.

Method evaluation of the reported method on chiralcel OJ-H column was performed with a mobile phase a mixture of hexane, isopropyl alcohol, and ethanolamine. In this method, both enantiomers were separated but the method is non-selective. The d-mandelic acid used for the resolution of the racemic 1-(4-Methoxybenzyl)-1,2,3,4,5,6,7,8-octahydroisoquinoline is not eluting in this method. Mandelic acid gets eluted after increasing composition of isopropyl alcohol but both enantiomers were found merging. Using the same mobile phase composition chiralpak AD-H column with stationary phase amylose tris(3,5dimethylphenylcarbamate) was tried. Here enantiomers were not separated base to base and peaks were asymmetrical with tailing factor more than 2.0 refer Figure 3. Maximum resolution of more than 4.0 with clearly separated peaks was observed on two stationary phases namely chiralpak IG-3 i.e. amylose tris(3chloro-5-methylphenylcarbamate) and Lux Amylose-2 i.e. amylose tris(2-methyl-5-chlorophenylcarbamate). Enantiomer peaks were symmetrical but D-mandelic acid was not eluting out from the column. Refer Figures 4 and 5. After few trials of stationary and mobile phases chiralpak ID-3 column was selected where both enantiomers were resolved as well as D-mandelic acid and other known process impurities also eluting out from the column. Chiralpak ID-3 column i.e. amylose tris(3chlorophenylcarbamate) immobilized on $3 \mu \mathrm{m}$ silica gel was found suitable for the analysis. Here (S)-1-(4-Methoxybenzyl)$1,2,3,4,5,6,7,8$-octahydroisoquinoline is eluting at a retention time (RT) 6.1 minutes and unwanted $\mathrm{R}$ enantiomer at 8.0 minutes. With gradient elution of methanol and acetonitrile, D-mandelic acid was eluting at RT 15.2 minutes. In the mixture of methanol and acetonitrile as mobile phase, both enantiomers were separated base to base but peaks were not symmetrical having tailing more than 4.0. The core structure of the analyte consist of octahydroisoquinoline which is secondary amine has strongest basic $\mathrm{pKa}$ 9.36. On basis of the chemical property of the compound decided to add basic additive diethylamine in the mobile phase and found both enantiomer peaks were become sharp and symmetrical without compromising resolution.

\section{Analytical method validation}

\section{Selectivity}

Selectivity is the ability of the method to determine accurately and specifically the analyte of interest in the presence of other components in a sample matrix that may be expected to be present in the sample matrix under the stated conditions. Selectivity of the method was evidenced by comparing blank, $\mathrm{R}$ and $\mathrm{S}$ isomers of 1-(4-Methoxybenzyl)-1,2,3,4,5,6,7,8octahydroisoquinoline and other specified impurities separate injections. There is no interfering peak at the retention time of $\mathrm{R}$ and $\mathrm{S}$ isomers of 1-(4-Methoxybenzyl)-1,2,3,4,5,6,7,8octahydroisoquinoline observed. Both isomer peaks were well resolved from all another specified impurity. Refer Figure 6 of a chromatogram of $\mathrm{R}$ and $\mathrm{S}$ isomers of 1-(4-Methoxybenzyl)1,2,3,4,5,6,7,8-octahydroisoquinoline standard solution. Refer Figure 7 of a chromatogram of unwanted $R$ enantiomer is spiked in the standard solution of (S)-1-(4-Methoxybenzyl)-1,2,3,4,5,6,7,8octahydroisoquinoline.

\section{Solution stability}

Drug stability in Active Pharmaceutical Ingredient (API) is a function of storage conditions and chemical properties of the drug and its impurities. The solution stability till nine hours of 1-(4-Methoxybenzyl)-1,2,3,4,5,6,7,8-octahydroisoquinoline was checked by injecting standard and spike system suitability solutions separately. Both solutions were prepared fresh before injection 
and immediately injected and same were injected after nine hours. The peak area of $\mathrm{R}$ and $\mathrm{S}$ isomers of 1-(4-Methoxybenzyl)$1,2,3,4,5,6,7,8$-octahydroisoquinoline of the freshly prepared standard solution was observed 201998 and 218382 after nine hours it was 202366 and 218803 respectively. Thus, no significant change in $\mathrm{R}$ and $\mathrm{S}$ isomers was observed till nine hours. Similarly, solution stability of system suitability solution was checked. In a fresh solution area of R, enantiomer was 483966 and it was found unchanged 483214 till fifteen hours.

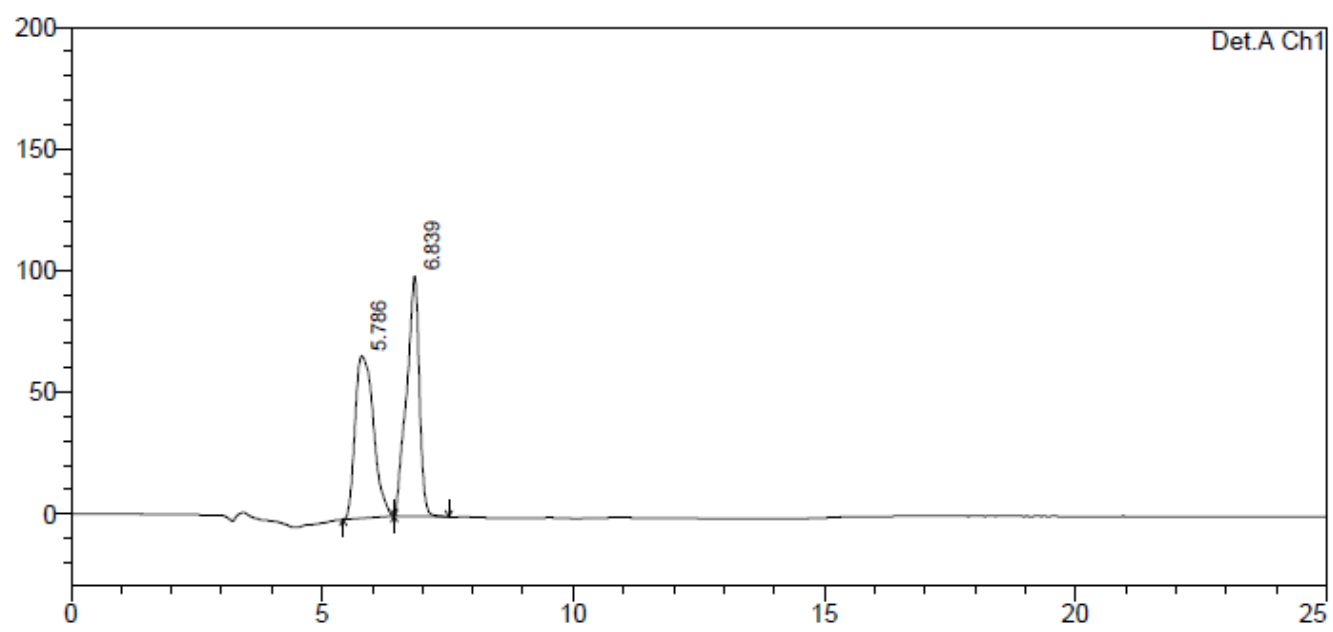

Fig. 3: Chromatogram of isomers partially resolved on chiralpak AD-H column.

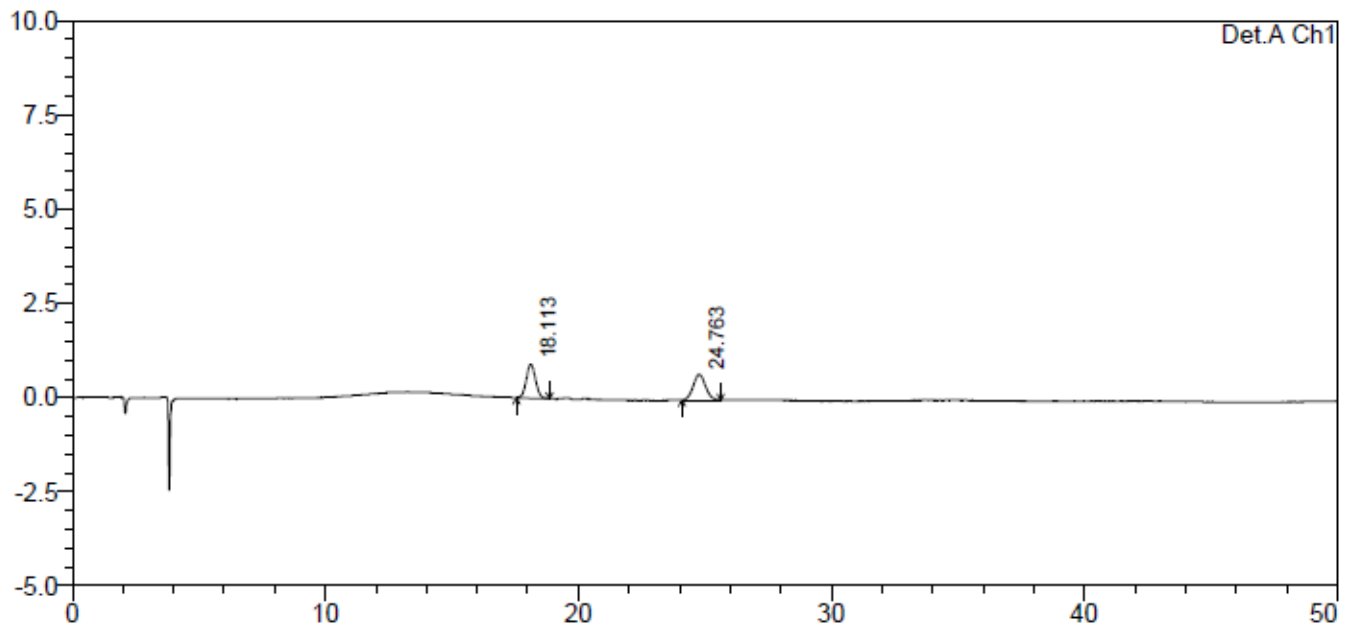

Fig. 4: Chromatogram of isomers well resolved on chiralpak IG-3 column.

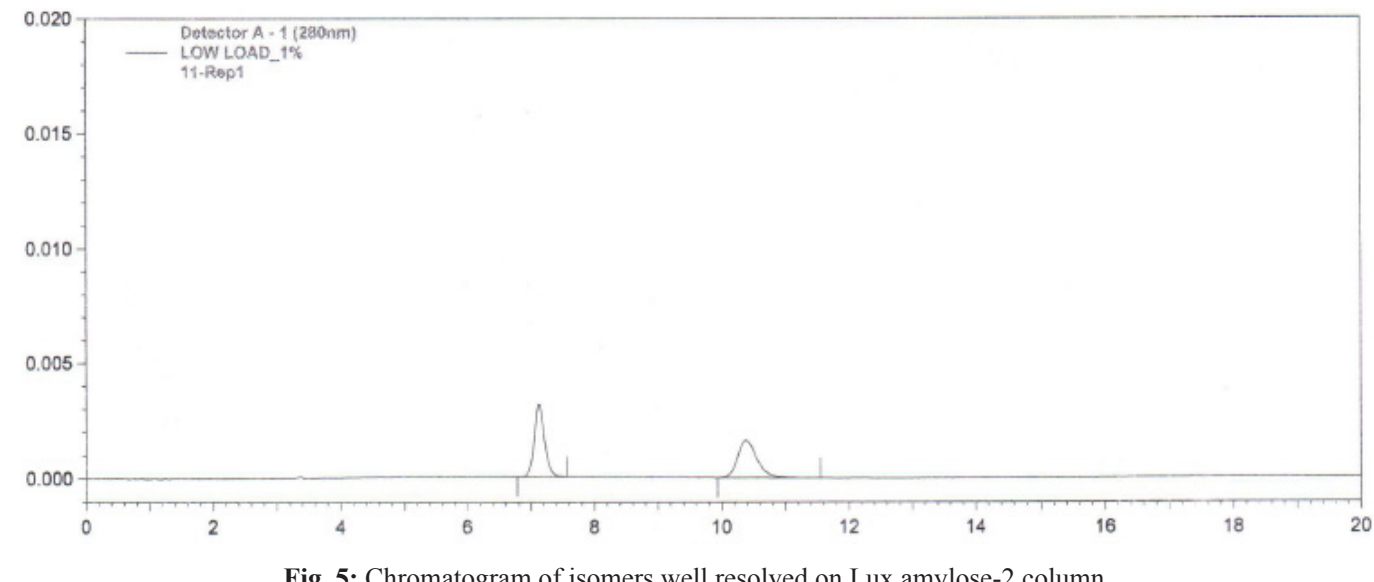

Fig. 5: Chromatogram of isomers well resolved on Lux amylose-2 column. 


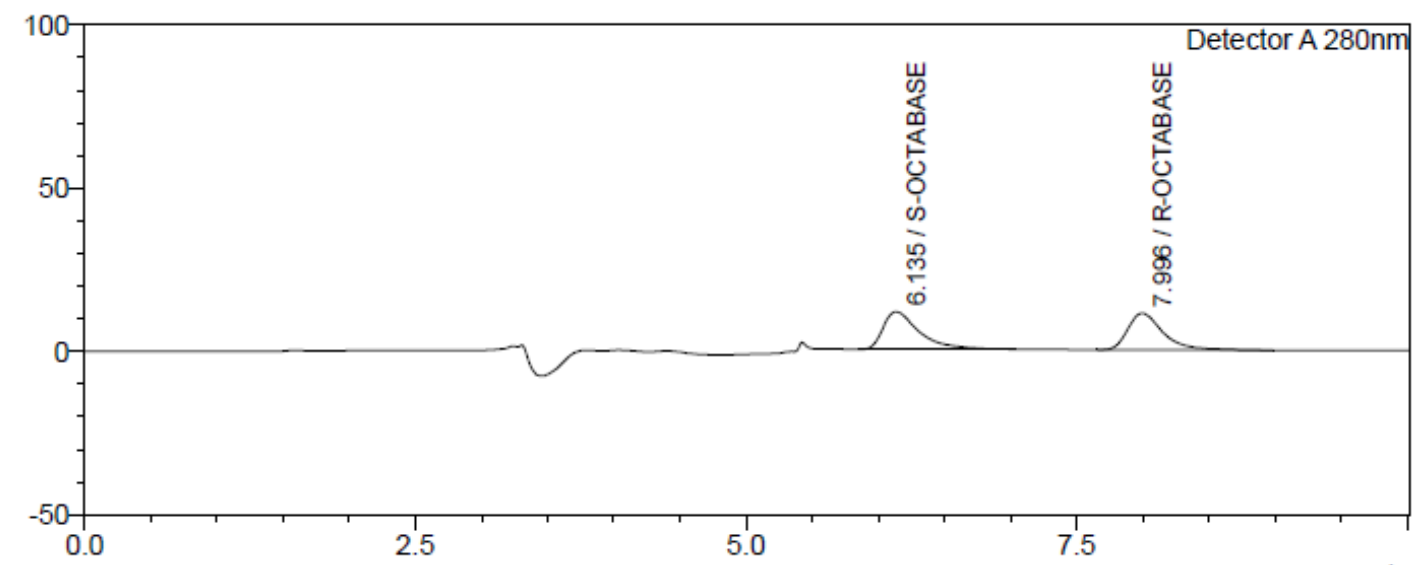

Fig. 6: $\mathrm{R}$ and $\mathrm{S}$ isomers of 1-(4-Methoxybenzyl)-1,2,3,4,5,6,7,8-octahydroisoquinoline standard solution chromatogram on chirlpak ID-3 column.

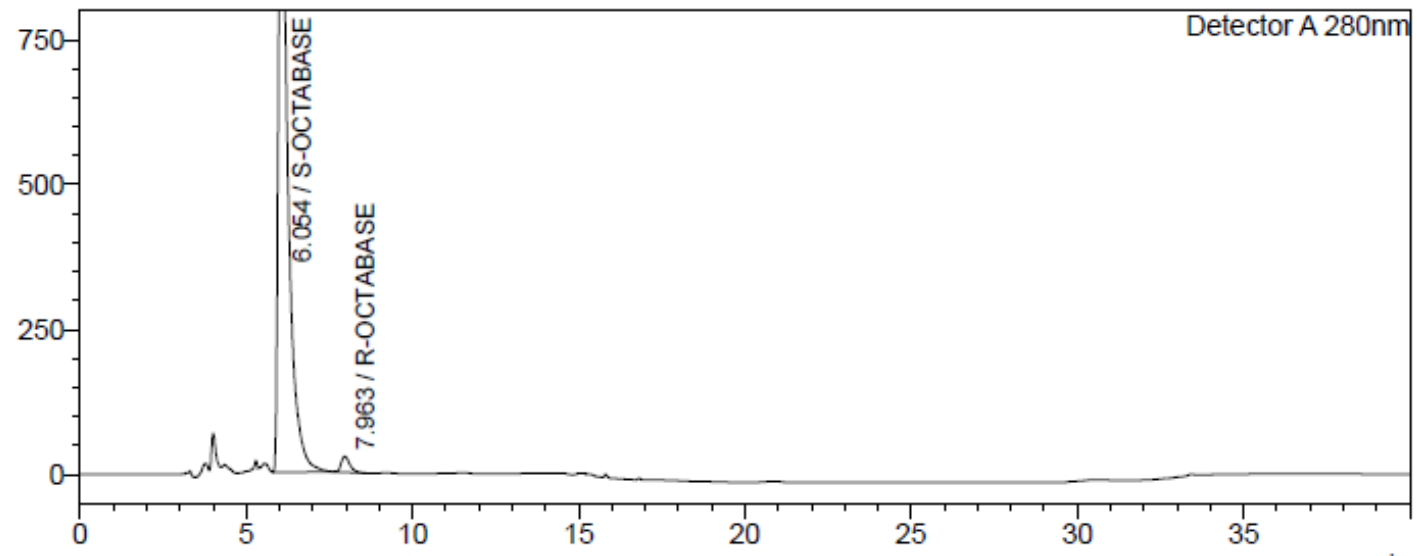

Fig. 7: Chromatogram of (S)-1-(4-Methoxybenzyl)-1,2,3,4,5,6,7,8-octahydroisoquinoline standard solution spiked with unwanted R enantiomer on chirlpak ID-3 column.

\section{Limit of detection and quantification}

The limit of detection (LOD) is the lowest concentration of the analyte in a sample that can be detected but not necessarily quantified. The obtained LOD value of (R)-1-(4-Methoxybenzyl)$1,2,3,4,5,6,7,8$-octahydroisoquinoline is discussed.

$$
\mathrm{LOD}=3.3 \times \sigma / \mathrm{S}
$$

The limit of quantitation (LOQ) is the lowest concentration or amount of the analyte that can be determined quantitatively within an acceptable level of repeatability precision and trueness.

$$
\mathrm{LOQ}=10.0 \times \sigma / \mathrm{S}
$$

Where, $\sigma=$ the standard deviation of the response and $\mathrm{S}=$ slope of the calibration curve

LOD and LOQ concentration of unwanted R enantiomer are reported with respect to (S)-1-(4-Methoxybenzyl)$1,2,3,4,5,6,7,8$-octahydroisoquinoline test solution concentration. LOD is $0.0075 \%$ i.e. $0.075 \mathrm{mg} / \mathrm{g}$ and LOQ is $0.025 \%$ i.e. 0.25 $\mathrm{mg} / \mathrm{g}$. The precision of LOQ is checked by injecting six replicate injections. Relative standard deviation (RSD) of the peak area of
(R)-1-(4-Methoxybenzyl)-1,2,3,4,5,6,7,8-octahydroisoquinoline at LOQ level is observed $1.25 \%$ which proves consistency and reproducibility of the method at a low level.

\section{Linearity}

Under the experimental conditions, the peak area of unwanted $\mathrm{R}$ enantiomer vs. concentration plot for the proposed method was found to be linear over the range of LOQ level, 25\%, $50 \% 100 \%, 120 \%$ and $150 \%$ of the specified limit with a regression coefficient is 0.999 . The regression coefficient $\left(\mathrm{r}^{2}\right)$ more than 0.99 is generally considered as evidence of an acceptable fit of the data to the regression line. Refer Figure 8 of linearity plot where the concentration of (R)-1-(4-Methoxybenzyl)-1,2,3,4,5,6,7,8octahydroisoquinoline standard was plotted on abscissa that is independent variable and peak area is on the ordinate.

\section{Accuracy}

Accuracy can be defined as the closeness of agreement between a test result and the accepted reference value. The accuracy of the method was determined by recovery study. Analytical method may be considered validated in terms of accuracy if the mean value is within $\pm 20 \%$ of the actual value. During recovery study (S)-1-(4-Methoxybenzyl)-1,2,3,4,5,6,7,8- 
octahydroisoquinoline batch was analyzed and then $\mathrm{R}$ enantiomer was spiked in the (S)-1-(4-Methoxybenzyl)-1,2,3,4,5,6,7,8octahydroisoquinoline at LOQ level, $50 \%, 100 \%$ and $150 \%$ with respect to the limit of R-enantiomer that is $1.0 \%$. The recovery is found at $88.6 \%, 106.6 \%, 94.7 \%$ and $95.3 \%$ respectively which proves that the method is capable to quantify the analyte accurately and results are reliable even at trace level.

\section{Ruggedness study}

Ruggedness refers to the (intra-laboratory tested) behavior of an analytical process when small changes in the environment and/or operating condition are made. The ruggedness of the method was evaluated by estimating \% RSD of (R)-1(4-Methoxybenzyl)-1,2,3,4,5,6,7,8-octahydroisoquinoline standard solution tested by two different analysts on different days. One batch of (S)-1-(4-Methoxybenzyl)-1,2,3,4,5,6,7,8octahydroisoquinoline was spiked with unwanted R-enantiomer at $100 \%$ level and such six different preparations were prepared by each analyst. RSD of the content of R enantiomer of total twelve preparations was found to be $1.9 \%$, which proves that there is no variation in day to day analysis.

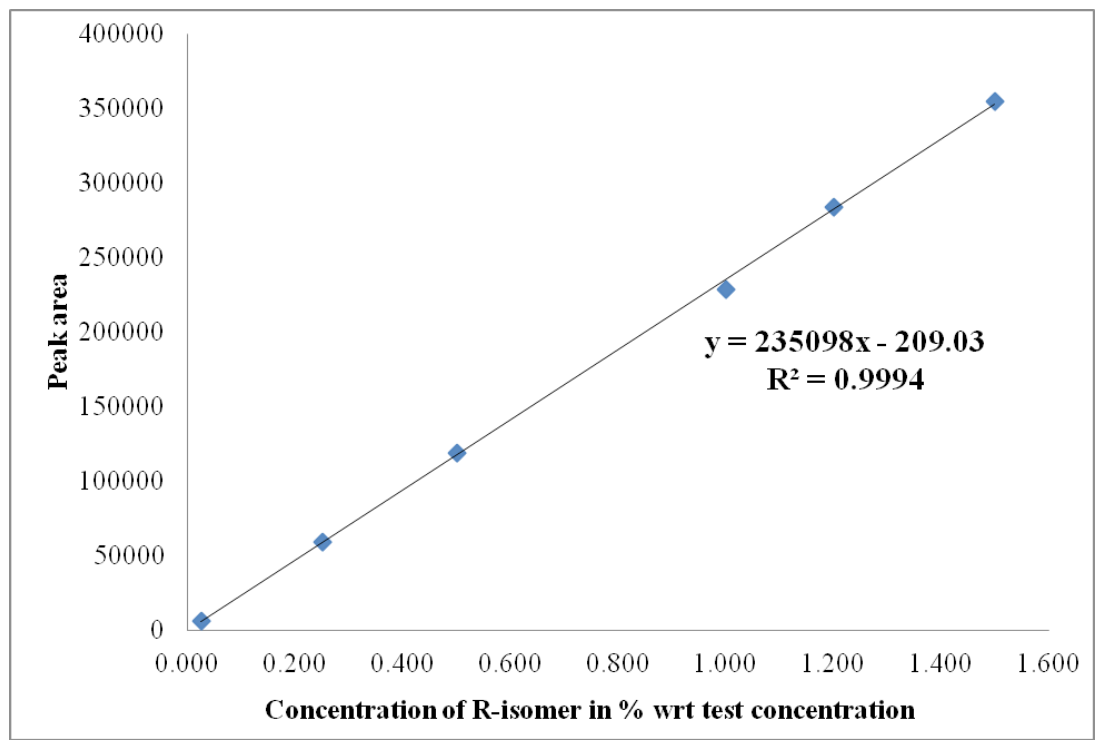

Fig. 8: Linearity plot of unwanted isomer (R)-1-(4-Methoxybenzyl)-1,2,3,4,5,6,7,8-octahydroisoquinoline.

Table 1. Method validation summary.

\begin{tabular}{|c|c|c|c|}
\hline S.NO. & PARAMETER & ACCEPTANCE CRITERIA & RESULTS \\
\hline 1 & Selectivity & $\begin{array}{l}\text { R and } S \text { enantiomer peaks should be well separated from all known and unknown peaks of } \\
\text { (S)-1-(4-Methoxybenzyl)-1,2,3,4,5,6,7,8-octahydroisoquinoline }\end{array}$ & Method is selective. \\
\hline 2 & Solution stability & Report Result & Solutions are stable up to $15 \mathrm{hrs}$ \\
\hline 3 & Limit of detection & LOD of $\mathrm{R}$ enantiomer & $0.0075 \%$ wrt test concentration \\
\hline 4 & Limit of quantification & LOQ of $R$ enantiomer & $0.025 \%$ wrt test concentration \\
\hline 5 & LOQ precision & $\%$ RSD for six replicates of LOQ level standard solutions is NMT: $10.0 \%$ & $1.3 \%$ \\
\hline 6 & Linearity & Correlation: NLT 0.99 & 0.999 \\
\hline 7 & Accuracy & $\begin{array}{l}\text { Recovery should be between } \\
\qquad 80 \% \text { to } 120 \%\end{array}$ & complies \\
\hline 8 & Method precision & $\%$ RSD for results of six test preparations is NMT: $10 \%$ & $0.75 \%$ \\
\hline 9 & Intermediate precision & $\begin{array}{c}\% \text { RSD for results of twelve test preparations (Method precision and Intermediate } \\
\text { precision) is NMT: } 10 \%\end{array}$ & $1.9 \%$ \\
\hline \multirow{2}{*}{10} & \multirow{2}{*}{$\begin{array}{l}\text { Robustness: Column temperature } \\
\qquad\left(35^{\circ} \mathrm{C} \text { and } 45^{\circ} \mathrm{C}\right)\end{array}$} & $\% \mathrm{RSD}$ of $\mathrm{R}$ enantiomer at $35^{\circ} \mathrm{C}$ & $2.5 \%$ \\
\hline & & $\% \mathrm{RSD}$ of $\mathrm{R}$ enantiomer at $45^{\circ} \mathrm{C}$ & $1.0 \%$ \\
\hline
\end{tabular}

\section{Robustness study}

Robustness is a measure of the capacity of the analytical procedure to remain unaffected by small but deliberate variations in method-performance parameters, which provides an indication of its reliability during normal usage. Robustness of the method was determined by analyzing the standard solution and $100 \%$ spike solution with a deliberate change in the critical parameter column temperature $\pm 5^{\circ} \mathrm{C}$. System suitability criteria were passing each time and RSD of $\mathrm{R}$ enantiomer peak area of six replicate preparations was observed 1.04. Refer to Table 1 of method validation summary.

\section{CONCLUSION}

The levomethorphan is an unwanted isomer of dextromethorphan hydrochloride drug substance. The chiral center is generated during synthesis of key starting material i.e. (S)-1-(4-Methoxybenzyl)- 1,2,3,4,5,6,7,8-octahydroisoquinoline. The $\mathrm{R}$ enantiomer of 1-(4-Methoxybenzyl)-1,2,3,4,5,6,7,8- 
octahydroisoquinoline is leading to the formation of the unwanted levomethorphan. Here the quantification of $\mathrm{R}$ enantiomer in (S)-1-(4-Methoxybenzyl)-1,2,3,4,5,6,7,8-octahydroisoquinoline method was developed to control the further formation of levomethorphan in the final drug product. The proposed method was validated as per ICH guideline and checked for accuracy and reliability of the result. The chiral HPLC method satisfies all validation parameters like system suitability, precision, specificity, accuracy, the linearity of detector response, ruggedness and robustness. It indicates that the method is stable and suitable for the quantification of R enantiomer in the KSM of dextromethorphan. Hence, the validated method can be used for routine analysis in quality control laboratories in the pharmaceutical industry.

\section{ACKNOWLEDGMENT}

Authors are thankful to the management of Wanbury Limited for their constant support.

\section{COMPLIANCE WITH ETHICAL STANDARDS}

\section{Conflict of Interest}

Author Ajit Anerao, Vishal Solase, Amol More, Nitin Pradhan declare that they have no conflict of interest.

\section{Ethical Approval}

This article does not contain any studies with human participants or animals performed by any of the authors.

\section{REFERENCES}

Bortolotti F, Bertaso A, Gottardo R, Musile G, Tagliaro F. Dextromethorphan/Levomethorphan issues in a case of Opiate overdoe. Drug Test and Ana, 2013; 5:781-784.

CAS. Chemical Abstracts Service. 2018; Available at: http:// www.chemnet.com/cas/supplier.cgi?terms $=30356-07-1 \& 1=$ en\&exact=dict $\& \mathrm{f}=$ plist\&mark $=\&$ submit. $\mathrm{x}=0$ \&submit. $\mathrm{y}=0$ [Accessed 12 Jan 2018].

Cersósimo M, Micheli F. Antiglutamatergic drugs in the treatment of Parkinson's disease. Handbook of Clinical Neurology. 2007; 84: 127-136.

Divi et al. Resolution of 1-(4-Methoxybenzyl)-1,2,3,4,5,6,7,8octahydroisoquinoline. Patent No. US 8,148,257 B1. 2012.

Demian et al. Separation of Enantiomers of Octahydroisoquinoline. Patent No. US 006063925 A. 2000.

EP 9.0. Dextromethorphan hydrobromide. The European Directorate for the Quality of Medicines \& HealthCare, 2017; 2233-2234.

Guangyue Li, Peiyuan Y, Peiqian C, Jie R, Lei W, Jinhui F, Peter
C, Qiaqing W, Dunming Z. New recombinant cyclohexylamine oxidase variants for deracemization of secondary amines by orthogonally assaying designed mutants with structurally diverse substrates. Sci. Rep. 2016; ID 24973.

ICH. Impurities in new drug substances. Q3A(R2). ICH harmonised tripartite guideline. 2006.

ICH. Validation of analytical procedures: Text and methodology. Q2 (R1). ICH Harmonised Tripartite Guideline. 2005.

Kikura R., Kawamura M, Miyajima A, Sunouchi M, Goda Y. Chiral analyses of dextromethorphan/levomethorphan and their metabolites in rat and human samples using LC-MS/MS. Anal. Bioanal Chem, 2011; 400:165-74.

Krait S, Heuermann M, Scriba G. Development of a capillary electrophoresis method for the determination of the chiral purity of dextromethorphan by a dual selector system using quality by design methodology. J Sep Sci, 2018; 41:1405-1413.

Lurie I, Kimberly A. Rapid Chiral Separation of Dextro- and LevoMethorphan using Capillary. Electrophoresis with Dynamically Coated Capillaries. Microgram J, 2005. 3:138-141; Available at: http://forendex. safs 1966.org/uploads/references/MicrogramJournal/3.3-4.138.141.pdf [Accessed 05 Feb 2018].

Magellan Rx Management. Cough and Cold Therapeutic Class Review. 2016; Available at: https://hhs.texas.gov/sites/default files/documents/about-hhs/communications-events/meetings-events/ dur/042817-4o.pdf [Accessed 05 Feb 2018].

Nuedexta. Dextromethorphan. EMA/CHMP/80029/2013 European Medicines Agency. EMA. 2013.

PDR. Dextromethorphan hydrobromide-Drug summary Prescribers Digital Reference. 2018; Available at: http://www.pdr.net/ drug-summary/Maximum-Strength-Mucinex-DM-dextromethorphanhydrobromide-guaifenesin-2165 [Accessed 21 Jan 2018].

Pharmeuropa. Dextromethorphan hydrobromide Monohydrate. Reference: PA/PH/Exp. 11/T (17) 98 ANP. The European Directorate for the Quality of Medicines \& HealthCare, 2017; 2233-2234; Available at http://pharmeuropa.edqm.eu/TextsForComment [Accessed 02 Jan 2018].

Rxlist. 2017. Available at: https://www.rxlist.com/nuedextadrug.htm [Accessed 05 Jan 2018].

Sigma-Aldrich. 2018; Available at: https://www.sigmaaldrich $\mathrm{com} /$ catalog/product/aldrich/539007?lang=en\&region=IN [Accessed 21 Jan 2018].

USP 40. Dextromethorphan hydrobromide. The United States Pharmacopeial Convention, 2017; 3705-3707.

How to cite this article:

Anerao A, Solase V, More A, Pradhan N. Separation, Quantification and Control of Enatiomers of the Key Starting Material of Dextromethorphan Hydrobromide. J App Pharm Sci, 2018; 8(08): 032-038. 